\title{
Occupational Exposure and Co-Occurrence of Work-Related Skin and Respiratory Disorder in Cleaner: A Case Report
}

\author{
Jordan Minov $^{1 *}$, Jovanka Karadzinska-Bislimovska ${ }^{1}$, Engin Tutkun ${ }^{2}$, Sasho Stoleski ${ }^{1}$, Dragan Mijakoski ${ }^{1}$ \\ ${ }^{1}$ Institute for Occupational Health of Republic of Macedonia, Skopje - WHO Collaborating Center and GA2LEN Collaborating \\ Center, Skopje, Republic of Macedonia; ${ }^{2}$ Ankara Occupational Diseases Hospital, Ankara, Turkey
}

Citation: Minov J, Karadzinska-Bislimovska J, Tutkun E, Stoleski S, Mijakoski D. Occupational Exposure and CoCleaner: A Case Report. SEE J Immunol. 2016 Jan 08; 2016:20006. http://dx.doi.org/ 10.3889/seejim.2016.20006 Key words: allergic occupational contact dermatis; cleaner; Key words: allergic occupational contact dermatitis; cleaner asthma; skin prick test.

Correspondence: Jordan B. Minov, MD, PhD. Department of ardiorespiratory Functional Diagnostics, Institute for ccupational Health of R. Macedonia - WHO Collaborating Center and GA2LEN Collaborating Center, II Makedonsk Fax: + 38922621 428. E-mail: minovj@hotmail.com

Received: 09-Nov-2014; Revised: 29-Dec-2014; Accepted: 01-Jan-2016; Published: 06-Jan-2016

Copyright: () 2016 Jordan Minov, Jovanka KaradzinskaCopyright: 2016 Jordan Minov, Jovanka KaradzinskaThis is an open-access article distributed under the terms of the Creative Commons Attribution-NonCommercial 4.0 International License (CC BY-NC 4.0).

Competing Interests: The author have declared that no competing interests exis.

\begin{abstract}
BACKGROUND: Despite the connection between skin and respiratory system in occupational disease is growing area of research interest, there is still a limited evidence for the effects of both airborne and skin exposures together with skin and respiratory outcomes.

CASE PRESENTATION: This report describes a 32-years old female with no previous history of atopy, asthma or skin disorders working as an office cleaner for three years. About two years after entering the actual workplace she developed episodic wheezing, shortening of breath and chest tightness. At the same time, she noticed eczematous lesions on the skin of both hands. She reported work-relatedness of both respiratory and skin symptoms, i.e. the symptoms improved during weekends and holidays and worsened when she returned to work. The patient was referred to Institute for Occupational Health of R. Macedonia for assessment of possible occupational asthma (OA) and occupational contact dermatitis (OCD). Diagnosis of asthma was confirmed by standard diagnostic procedure, while the diagnosis of sensitizer-induced OA was established by positive result of serial peak expiratory flow rate (PEFR) measurements at and away from work. Diagnosis of allergic OCD was confirmed by positive patch test to formaldehyde. The management of both diseases included complete removal from the harmful workplace exposure, as well as pharmacological treatment according to the actual recommendations.
\end{abstract}

CONCLUSIONS: This case report represents a description of a co-occurrence of work-related skin and respiratory symptoms in a female working as an office cleaner. Formaldehyde is found to be a causative factor of allergic OCD, and it also may be a causative factor of sensitiveinduced $\mathrm{OA}$ in the same patient, but other occupational sensitizers cannot be excluded.

\section{Introduction}

The connection between skin and respiratory system in occupational disease is growing area of research interest but the associations between exposure and symptoms, as well as the relationship between skin and respiratory effects are still unclear.

The hypotheses of how the skin and the lung may interact in terms of exposure and outcomes are complex. If a worker is sensitized due to dermal exposure, a respiratory response may be triggered by relatively low airborne exposure. This has implications for exposure control because airborne exposure limits may prevent airways sensitization but may not be protective for elicitation in the airways of a sensitized worker [1].
Despite the case reports of co-occurring skin and respiratory disease attributed to occupational exposures, there is still very limited research in working populations regarding the co-existence of these outcomes. There are many studies of respiratory symptoms in working populations, comparatively not so much studies of dermal symptoms in working populations, but only few publishing studies that reported on co-existing skin and respiratory symptoms in certain occupations [2-5]. Results from the study carried on by Lynde et al. [6] which was focused on skin and respiratory symptoms in a group of professional cleaners showed that those cleaners with a current rash or a rash in the last twelve months were at significantly increased odds of reporting work-related respiratory symptoms compared with cleaners who did not have a rash. 
The aim of this case report is to present a cooccurrence of work-related skin and respiratory symptoms in a female working as an office cleaner.

\section{Diagnostic work-up}

The diagnostic work-up in this case began with clinical and working history taking, clinical examination and spirometry. Skin prick tests (SPTs) to common inhalant allergens (birch, lime, grass mixed, plantain, Dermatophagoides pteronyssinus, fungi mixed, dog hair, cat fur, and feathers mixed) was performed and interpreted according to the actual recommendations [7]. Atopy was defined as a presence of at least one positive SPT to common inhalant allergens [8].

Bronchial responsiveness was evaluated by metacholine challenge test according to the actual recommendations $[9,10]$. The diagnosis of asthma was based on the history of asthmatic symptoms and positive metacholine challenge test [11]. The workrelatedness of asthma was evaluated by serial peak expiratory flow rate (PEFR) measurements according to the actual recommendations $[12,13]$. The diagnosis of $O A$ (sensitizer-induced $O A$ ) was established by finding of significant changes of the PEFR values registered in the periods at and away from work [14].

Patch tests to common occupational contact allergens (potassium bichromate, nickel sulphate, cobalt chloride, p-phenylenediamine, formaldehyde, thiuram mix, neomycin sulphate, balsam of Peru, latex and epoxy resin) was performed and interpreted according to the actual recommendations of the European Society of Contact Dermatitis guideline for diagnostic patch testing. Work-related eczematous skin lesions followed by positive patch test to certain common occupational contact allergen indicated diagnosis of allergic OCD [15-17].

\section{Results}

A 32-years old never-smoking female with no previous history of asthma or skin disorders worked as an office cleaner for three years. Her working tasks included dusting, washing and polishing surfaces, walls and floors, as well as disposing of waste and wasted water. The workplace exposure included several types of cleaning products, such as soaps and detergents, disinfectants, solvents, and polishes; some of which being in spray form. These cleaning products contained several agents capable of causing irritation or/and allergic sensitization, such as their active compounds (chlorine, ammonia, caustic soda, etc.), preservatives (formaldehyde, isothiozolinones, etc.), corrosion inhibitors (ethanolamines), biocides (quaternary ammonium compounds), scents (lemon, spine, etc.) etc. She usually, but not all the time during the work, used the protective equipment during her working (protective clothing, gloves and mask).

About two years after entering the actual workplace she developed episodic wheezing, shortening of breath and chest tightness. At the same time, she noticed eczematous lesions (redness, swelling, itching and fluid-filled blisters) on the skin of both hands. She reported work-relatedness of both respiratory and skin symptoms, i.e. the symptoms improved or disappeared during weekends and holidays and worsened or occurred when she returned to work. The patient was referred to Institute for Occupational Health of Republic of Macedonia for assessment of possible occupational asthma (OA) and occupational contact dermatitis (OCD).

At the time of diagnostic procedure, the patient (being about one month away from work) had neither respiratory symptoms nor skin lesions. There was no any respiratory or skin sign by clinical examination, the spirometric measurements showed normal values of the spirometric parameters, and skin prick tests to standard inhalant allergens were negative. Bronchial hyperresponsiveness (BHR) was registered by metacholine challenge (the metacholine provocative concentration that caused felt of FEV1 of $20 \%$ or more by its basal value was $1.23 \mathrm{mg} / \mathrm{mL}$ ) suggesting the diagnosis of asthma. The workrelatedness of the disease was assessed by serial PEFR measurements at and away from work. Significant changes of the PEFR values registered at work compared to the PEFR values registered in the period away from work suggested diagnosis of sensitizer-induced OA.

Patch testing with common patch allergens showed positive result to formaldehyde suggesting the diagnosis of occupational OCD.

The treatment was initiated according to the actual recommendations. As the basis of both respiratory and skin disease was found to be occupational allergy, complete removal from the actual workplace was recommended.

\section{Discussion}

$O A$ and $O C D$ are common problems in the workplace (i.e. workers can develop new disease, or aggravate existing disease, as a result of occupational exposures) and both diseases have an allergic and irritant form. In addition, there is evidence that some workers experience both respiratory and dermal symptoms, and that these symptoms may occur as a result of occupational exposure. There is evidence 
that skin exposure may lead to sensitization that is relevant to the development of respiratory disease, i.e. that several common occupational exposures may cause disease in both the skin and respiratory system. On the other side, neither of these two areas, concurrent symptoms and cross-system sensitization, has been explored thoroughly in occupational studies [18].

There is significant overlap in agents/exposures that may cause OA and OCD. Of the ten most frequent occupational contact allergens (OCAs) (epoxy resins, thiuram, carba mix, nickel sulphate, cobalt chloride, potassium bichromate, glyceryl thioglycolate, P-phenylenediamine, formaldehyde, and glutarladehyde), seven wer listed in the Asthma in the Workplace as exposures capable of causing OA (all except thiuram, carba mix and thioglycolate) [19]. In addition, of the ten most frequent OCAs, epoxy resin, nickel sulphate, cobalt chloride, potassium dichromate and glutaraldehyde according to the systematic literature review were classified as having established association with $O A$. Formaldehyde and PPD were classified as possibly associated due to discrepance between the two reference documents [18].

This case report is a description of cooccurrence of work-related skin and respiratory symptoms in a 32-year old female working as an office cleaner for three years. She had not any dermal or respiratory problem before entering the actual workplace, i.e. the symptoms appeared two years after she began the actual work. Both dermal and respiratory symptoms occurred at the same time showing clear work-relatedness. She was referred to the Institute for Occupational Health of Republic of Macedonia, Skopje almost two years after occurrence of the symptoms being previously treated by general practitioner. At the Institute she underwent the standard diagnostic procedure and the diagnoses of allergic OCD caused by formaldehyde and sensitizerinduced OA were established. As we were unable to perform the specific inhalation challenge (SIC) with certain occupational agent, the causative factor of allergic-sensitized OA could not be detected. It may be formaldehyde, but other workplace agent could not be excluded. After the diagnosis was established, a treatment with asthma controller (inhalant corticosteroids in low dose) was initiated according to the actual recommendations of the Global Initiative for Asthma (GINA) [11]. At the same time, removal from the harmful workplace was strongly recommended.

Formaldehyde is commonly used as a preservative and disinfectant in cleaning products. Furthermore, formaldehyde may be released by other preservatives in cleaning products, i.e. by terpens, the main constituent of essential oils derived from oranges, lemons, other citrus, lavender, thyme, cedar wood, pine, and other plants, flowers, and trees that react with ozone from air pollution producing formaldehyde, acetaldehyde and other volatile carbonyls [20]. Formaldehyde is a low-weightmolecule (LMW) compound which may cause adverse healthy effects in exposed individuals, primary in exposed workers. Namely it is well established that formaldehyde may cause sensitizer-induced OA and allergic OCD in susceptible workers [21, 22]. As it is case with majority LMW agents, formaldehyde causes sensitizer-induced OA by mechanisms which do not include Immunoglobuline $\mathrm{E}$ ( $\mathrm{lg} \mathrm{E})$-mediated allergic reaction (i.e. non-lgE-mediated sensitizer-induced OA or IgE-independent sensitizer-induced OA), so allergic sensitization to formaldehyde can not be confirmed by skin prick test [23, 24]. On the other side, skin sensitization to formaldehyde occurs due to delayed type of hypersensitivity (IV type allergic reaction), so it can be demonstrated by patch test with this agent [22, 25]. In addition, by the International Agency for Research on Cancer (IARC), formaldehyde is classified as a known human carcinogen for laryngeal cancer [26].

Limitation of the present case report is that SIC was not performed and the causative agent of the sensitizer-induced OA was not documented. Although the SIC may produce false positive and false negative results, it is considered as a gold standard for diagnosis of sensitizer-induced OA. On the other side, this case report is a contribution to still poor evidence of the co-occurrence of skin and respiratory allergic disorders in outpatient settings.

In conclusion, this case report represents a description of a co-occurrence of work-related skin and respiratory symptoms in a female working as an office cleaner. Formaldehyde is found to be a causative factor of allergic OCD, and it also may be a causative factor of sensitive-induced $O A$ in the same patient, but other occupational sensitizers can not be excluded. As there is some evidence about the connection between skin and respiratory system in occupational disease, further studies are necessary to improve the knowledge for the effects of both airborne and skin exposures together with skin and respiratory outcomes. Additionally, there is a need for a more specific approach for diagnosis and management of the patients suffering from work-related skin and respiratory allergic disorders.

\section{Authors Participations}

JM participated in the study design, data collection, managing the analyses of the study, and writing all versions of the manuscript. JKB and TE participated in the study design, managing the analyses of the study, as well as writing all versions of the manuscript. SS and DM participated in the data collection and in the managing the analyses of the study. All authors read and approved the final manuscript. 


\section{References}

1. Moulin P, Magnan A, Lehucher-Michel MP. Occupational allergic contact dermatitis and asthma due to a single low molecular weight agent. J Occup Health. 2009; 51(1):91-96.

http://dx.doi.org/10.1539/joh.L7110 PMid:19057115

2. Jacobs JH, Meijster T, Meijer E, Suarthana E, Heederik D. Wheat allergen exposure and the prevalence of work-related sensitization and allergy in bakery workers. Allergy.

2008;63(12):1597-604

http://dx.doi.org/10.1111/.1398-9995.2008.01698.x PMid:18513267

3. Heldal KK, Madso L, Huser PO, Eduard W. Exposure, symptoms, and airway inflammation among sewage workers. Ann Agric Environ Med. 2010;17(2): 263-268. PMid:21186769

4. de Joode Bv, Vermeulen R, Heederik D, van Ginkel K, Kromhout $\mathrm{H}$. Evaluation of 2 self-administered questionnaires to ascertain dermatitis among metal workers and its relation with exposure to metalworking fluids. Contact Dermatitis. 2007;56(6):311-7. http://dx.doi.org/10.1111/i.1600-0536.2007.01111.x PMid:17577371

5. De Raeve H, Vandecasteele C, Demedts M, Nemery B. Dermal and respiratory sensitization to chromate in a cement floorer. Am J Ind Med. 1998;34(2):169-176.

http://dx.doi.org/10.1002/(SICl)1097-0274(199808)34:2<169::AIDAJIM10>3.0.CO:2-T

6. Lynde CB, Obadia M, Liss GM, et al. Cutaneous and respiratory symptoms among professional cleaners. Occup Med. 2009;59(4):249-254.

http://dx.doi.org/10.1093/occmed/kqp051

PMid:19433617

7. Bousquet J, Heinzerling L, Bachert $\mathrm{C}$, et al. Practical guide to skin prick tests in allergy to aeroallergens. Allergy. 2012;67:18-24. http://dx.doi.org/10.1111/.1398-9995.2011.02728.x PMid:22050279

8. Frew AJ. Allergic basis of asthma. Eur Respir Mon. 2003;23(8):74-83.

9. Sterk PJ, Fabbri LM, Quanjer PhH, et al. Airways Responsiveness. Standardized challenge testing with pharmacological, physical and sensitizing stimuli in adults. Report Working Party for the Standardization of Lung Function Tests. European Community for Steel and Coal. Official Statement of the European Respiratory Society. Eur Respir J. 1993;6(16):58-83.

10. American Thoracic Society. Guidelines for Metacholine and Exercise Challenge Testing -1999. Am Respir Crit Care Med. 2000;161(1):309-329.

http://dx.doi.org/10.1164/ajrccm.161.1.ats11-99 PMid:10619836

11. Global Initiative for Asthma. Global strategy for asthma management and prevention. NHLBI/WHO Workshop Report 2015. Available at: www.ginasthma.com (Assessed 26.10.2015)

12. Gannon PFG, Sherwood Burge P. Serial peak expiratory flow measurement in the diagnosis of occupational asthma. Eur Respir J. 1997;10(24):57-63.
13. Moore VC, Jaakkola MS, Sherwood Burge P. A systematic review of serial peak expiratory flow measurements in the diagnosis of occupational asthma. Annals of Respiratory Medicine. 2010:1:31-44

14. Tarlo SM, Balmes J, Balkisson R, et al. Diagnosis and management of work-related asthma. American College of Chest Physicians Consensus Statement. Chest. 2008;134:15-41. http://dx.doi.org/10.1378/chest.08-0201 PMid:18779187

15. Rietschel RL, Mathias CG, Fowler Jr. JF, et al. Relation of occupation to contact dermatitis: Evaluation of patients tested from 1998 to 2002. Am J Contact Dermat. 2002;13(4):170-176. http://dx.doi.org/10.1053/aicd.2002.36635 PMid:12478531

16. Uter W, Ramsch S, Aberer W, et al. The European baseline series in 10 European countries, 2005-2006--Results of the European Surveillance System on Contact Allergens (ESSCA). Contact Derm. 2009;61(1):31-38

http://dx.doi.org/10.1111/i.1600-0536.2009.01572.x PMid:19659962

17. European Society of Contact Dermatitis guideline for diagnostic patch testing. Available at:

http://www.escd.org/education/guidelines/ (Assessed 26.10.2016)

18. Arrandale VH. Occupational exposures and co-occurrence of work-related skin and respiratory symptoms. Available at: https://tspace.library.utoronto.ca/handle/ (Accessed 30.10.2015)

19. Bernstein IL, Chan-Yeung M, Malo J, Bernstein DI (eds). Asthma in the Workplace. 3rd ed. New York: Taylor and Francis, 2006.

http://dx.doi.org/10.3109/9780849374531

20. Cleaning agent. Available at: http://www.escd.org/education/guidelines/ (Assessed 27.10.2015).

21. Formaldehyde. Available at: www.truetest.com (Assessed 27.10.2015)

22. Mapp CE. Agents, old and new, causing occupational asthma. Occup Environ Med. 2001:58:354-360. http://dx.doi.org/10.1136/oem.58.5.35 PMid:11303086 PMCid:PMC1740131

23. Maestrelli $P$, Saetta M, Mapp CE, et al. Occupational asthma due to low-molecular weight compounds. In: Banks DE, Parker JE, eds. Occupational lung disease: an international perspective. New York: Chapman \& Hall Medical, 1998.

24. Sastre J, Vandenplas O, Park HS. Pathogenesis of occupational asthma. Eur Respi J. 2003;22:551-559. http://dx.doi.org/10.1183/09031936.03.00045103

25. Wolkoff P, Schneider T, Kildeso J, et al. Risk in cleaning: chemical and physical exposure. The Science of the Total Environment. 1998;215:135-156.

http://dx.doi.org/10.1016/S0048-9697(98)00110-7

26. IARC. Wood dust and formaldehyde. Lyon, International Agency for research on Cancer (IARC Monographs on the Evaluation of Carcinogenic Risk on Humans. 1995;62. 